\title{
Recombinant Lactococcus lactis expressing porcine insulin-like growth factor I ameliorates DSS-induced colitis in mice
}

\author{
Shujie Liu, Yongming Li, Bo Deng and Ziwei Xu*
}

\begin{abstract}
Background: Insulin-like growth factor I (IGF-I) is one important family of growth factors, which plays key role in intestinal growth, regeneration, and damage repair. However, the low natural abundance of IGF-I limits its research opportunities and practical application in the fields of medicine and animal husbandry. In this study, a tandem repeat strategy was used to express three copies of the same plGF-I $I_{3}$ protein in L. lactis. The activity of recombinant plGF-I $I_{3}\left(\right.$ rplGF-I $I_{3}$ ) was further examined by a mouse model of dextran sulfate sodium (DSS)-induced colitis. In

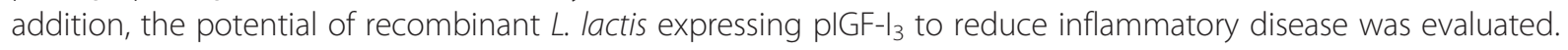

Results: plGF-I $\left.\right|_{3}$ could be expressed in L. lactis by the detection of SDS-PAGE and Western blot. Experimental colitis was induced in BALB/C mice by administration of $5 \%$ DSS in drinking water, and the clinical symptoms were

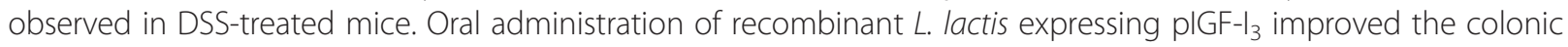
architecture, and significantly reduced the increase of colonic damage score $(P<0.05)$. Furthermore, recombinant $L$. lactis expressing plGF-I $I_{3}$ treatment significantly reduced serum DAO activity and colonic MPO level, and elevated colonic occludin level compared to the DSS group $(P<0.05)$.
\end{abstract}

Conclusions: The plGF-I $I_{3}$ expressed in L. lactis has good biological activity, and oral administration of recombinant $L$. lactis expressing plGF-I $I_{3}$ attenuated the symptoms and development of DSS-induced colitis in mice. These suggested that L. lactis could be a potential host bacterium for production and delivery of IGF-I against intestinal diseases.

Keywords: Insulin-like growth factor I, Lactococcus lactis, Colitis, Intestinal repair

\section{Background}

Insulin-like growth factor I (IGF-I) is a $7.5 \mathrm{kDa}$ singlechain polypeptide with 70 amino acid residues, which is considered as one important family of growth factors [1]. IGF-I is synthesized in the liver, produced locally in many tissues including the gastrointestinal tract, and regulated by growth hormone and nutrition [2, 3]. It exerts biological effect primarily through specific type I IGF receptor, which is distributed throughout the intestines of some mammalian, such as human, rat and pig [4, 5]. IGF-I can stimulate the proliferation and differentiation of many cell types, enhance DNA synthesis and protein content, inhibit cell apoptosis, and play an important role in the development and

\footnotetext{
*Correspondence: xzwfyz@163.com

Institute of Animal Husbandry and Veterinary Science, Zhejiang Academy of Agricultural Sciences, 145 Shiqiao Road, Hangzhou 310021Zhejiang, China
}

growth of animals [6-11]. In addition, IGF-I particularly displays trophic effect on the gastrointestinal tract, which has received considerable attention in the fields of medicine and animal husbandry.

Studies have indicated that IGF-I not only stimulated intestinal growth but also potentially regulated intestinal regeneration and repair. High concentrations of IGF-I in maternal colostrum and milk modulated neonatal gastrointestinal tract development and function [12]. IGF-I supplementation in newborn promoted nutrient and electrolyte absorption, improved intestinal morphology, and increased disaccharidase activity [13, 14]. In addition, orally or systemically administered IGF-I accelerated intestinal repair in animal models of intestinal diseases, such as experimental colitis, intestinal mucositis, and experimental radiation enteritis [15-17]. IGF-I has showed the potential to exert anti-inflammatory action by inhibiting pro- 
inflammatory cytokine production and increasing antiinflammatory cytokine production in acute pancreatitis [18].

IGF-I has important biological functions, but low abundance in natural sources is a crucial factor to limit its further study and practical application. Genetic engineering technique is a good method for low-cost production of functional proteins by large-scale culture of recombinant bacteria. Therefore, a safe and highly effective expression system is needed to produce functional proteins for the health of humans and animals. Human IGF-I has been produced in E. coli, but recombinant protein was expressed in insoluble inclusion bodies, and needed to be refolded into an active conformation by denaturation and renaturation treatment [19]. Probiotics has been reported to improve host health and modulate the gastrointestinal functions in human and animals [20]. Lactococcus lactis (L. lactis) is a food-grade microorganism widely used in the food fermentation industry and generally regarded as a safe probiotic [21]. Nonpathogenic and noninvasive $L$. lactis is an ideal candidate to produce and deliver therapeutic proteins to mucosal system of intestine with simple operation [22]. Furthermore, the bacterium can survive passage through human intestines and does not colonize the intestinal tract [23]. Foreign proteins expressed in L. lactis do not require to be purified, may be taken together with recombinant $L$. lactis, and can perform specific biological activity in body [24].

In the present study, three same genes of mature porcine IGF-I (pIGF-I ${ }_{3}$ ) were designed by tandem repeat strategy, and a nisin-controlled gene expression system (NICE) was used to express $\mathrm{pIGF}^{-\mathrm{I}_{3}}$ in L. lactis. The activity of recombinant PIGF- $\mathrm{I}_{3}$ (rpIGF- $\mathrm{I}_{3}$ ) was examined by using a mouse model of dextran sulfate sodium (DSS)-induced colitis, and the potential of recombinant

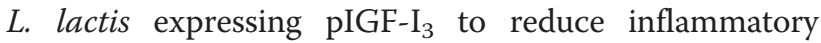
disease was evaluated.

\section{Results and discussion}

\section{Expression of plGF-I $\mathrm{I}_{3}$ in L. lactis}

The gene $\mathrm{PIGF}^{-\mathrm{I}_{3}}$ was optimized based on codon bias of L. lactis, and the restriction sites and a stop codon were added to the $3^{\prime}$ or $5^{\prime}$ end of the optimized $\mathrm{pIGF}-\mathrm{I}_{3}$ gene. The resulting fragment was cloned into pNZ8148 to generate pNZ8148-pIGF-I ${ }_{3}$, which had been successfully transformed into L. lactis NZ9000 by sequence identification. Whole cell lysates of L. lactis NZ9000 (pNZ8148pIGF- $\mathrm{I}_{3}$ ) were analyzed by using sodium dodecyl sulfate-polyacrylamide gel electrophoresis (SDS-PAGE) to determine whether $\mathrm{pIGF}^{-\mathrm{I}_{3}}$ could be expressed in $L$. lactis (Fig. 1a). The protein electrophoresis of the gel revealed an additional band of approximately $23 \mathrm{kDa}$, which just corresponded to the target protein of pIGF$\mathrm{I}_{3}$. However, L. lactis NZ9000 (pNZ8148) as control

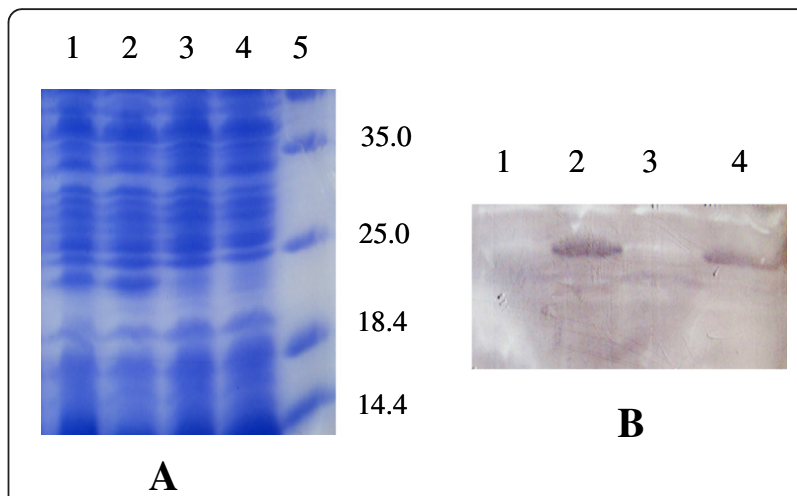

Fig. 1 Detection of rplGF-I $\left.\right|_{3}$ by SDS-PAGE (a) and Western blot (b) analysis of cell lysates of L. lactis NZ9000 (pNZ8148-p|GF-I I $_{3}$ induced with nisin. a Lanes 1 and 2, cell lysates of L. lactis NZ9000 (pNZ8148-plGF-| $\left.\right|_{3}$ ); lanes 3 and 4, cell lysates of L. lactis NZ9000 (pNZ8148); lane 5, molecular weight marker. b Lanes 1 and 3, cell lysates of L. lactis NZ9000 (pNZ8148); lanes 2 and 4, cell lysates of L. lactis NZ9000 (pNZ8148-plGF-| l )

strain did not have this band. The rpIGF- $\mathrm{I}_{3}$ was further assayed by Western blot, and the result revealed that the corresponding immunoreactive band was present on the membrane from L. lactis NZ9000 (pNZ8148-pIGF- $\mathrm{I}_{3}$ ) (Fig. 1b). These results indicated that L. lactis was able to express PIGF-I ${ }_{3}$.

\section{Colon length analysis}

The reduction of colon length was an indirect marker of colonic inflammation and often observed in ulcerative colitis patients or animal models [25]. Treatment with $5 \%$ DSS significantly shortened colon length $(31.67 \%)$ compared with the control group $(P<0.05)$. However, oral administration of recombinant $L$. lactis expressing $\mathrm{pIGF}^{-\mathrm{I}_{3}}$ or $L$. lactis improved the shortening of colon length (Fig. 2). Dietary colostrum-borne IGF-I during one week has been reported to promote the growth of neonatal intestinal tissue and up-regulated type I IGF receptors in newborn calves [26]. In addition, IGF-I treatment partially reversed significant reduction of colon length in DSS-treated rats, and reduced the thickness of submucosal and muscularis externa layers [27]. In the present study, oral administration of re-

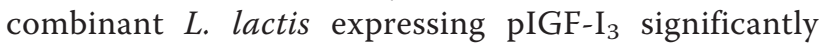
increased colon length by approximately $18.03 \%$ compared with the DSS group $(P<0.05)$, but no significant difference was found between the recombinant L. lactis and L. lactis groups. These suggested that recombinant $L$. lactis expressing $\mathrm{PIGF}-\mathrm{I}_{3}$ attenuated the shortening of colon length due to the use of L. lactis as a host bacterium, and took a certain protective effect on intestinal injury. 


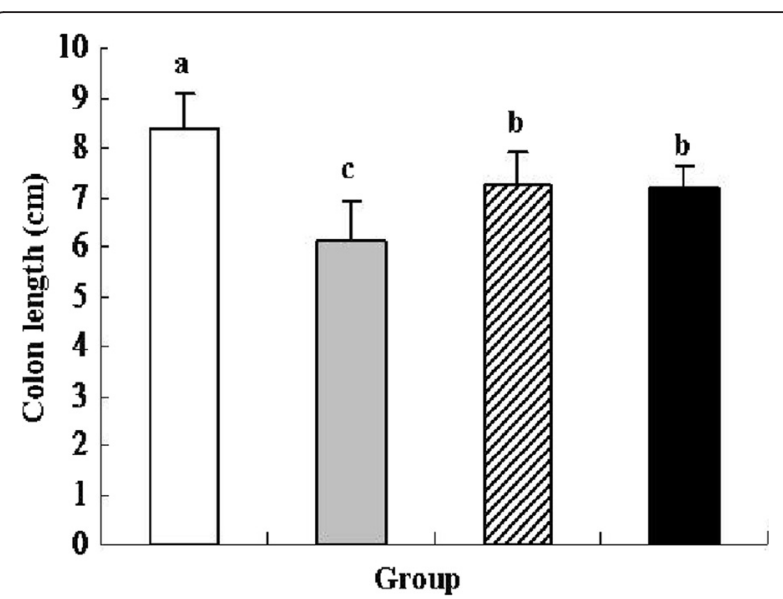

Fig. 2 Effect of oral administration of L. lactis NZ9000 (pNZ8148plGF-I $\left.{ }_{3}\right)$ on colon length in mice $(n=8)$ treated with DSS-induced colitis. The statistical differences between groups were evaluated by one-way ANOVA with Duncan's multiple comparison. Group 1 (control $\square$ ) received normal drinking water. Group 2 (DSS $\square$ received DSS solution in drinking water. Group 3 (L. lactis $\mathbf{Z}$ ) received the same treatment of DSS as Group 2. Meanwhile, these mice orally administered with L. lactis NZ9000 (pNZ8148). Group 4 (recombinant L. lactis received the same treatment of DSS as Group 2. Meanwhile, these mice orally administered with L. lactis NZ9000 (pNZ8148- plGF-I). Same letters between the groups indicate no statistically significant difference $(P>0.05)$, and different letters indicate statistically significant difference $(P<0.05)$

\section{Colonic damage score and histological analysis}

Colonic damage was observed on the 11th day of the experiment by histological detection (Fig. 3). DSS treatment revealed a typical ulcer that involved most of intestine mucosa, seriously affected colonic architecture, and led to a significant increase in colonic damage score (CDS) compared with the control group $(P<0.05)$. As vector control, $L$. lactis strain treatment showed visible large ulcer surface, peripheral epithelial cells crawling to the ulcer surface, damage being repaired in the colonic tissue and a significant reduction CDS compared with the DSS group $(P<0.05)$. In the recombinant $L$. lactis group, the morphological structure of colonic tissue became relatively complete, and colon displayed visible small ulcer surface. In addition, oral administration of recombinant $L$. lactis expressing pIGF- $\mathrm{I}_{3}$ further improved colonic damage, and significantly reduced CDS compared with the DSS and L. lactis groups $(P<0.05)$. These results suggested a direct action of recombinant $L$. lactis expressing $\mathrm{pIGF}^{-\mathrm{I}_{3}}$ on the colonic epithelium.

It has been reported that exogenously applied IGF-I increased the numbers of goblet cells of the colonic epithelium, and significantly increased histological healing scores in an experimental model of colitis [27, 28]. Administration of IGF-I to cirrhotic rats improved intestinal histopathological changes and significantly reduced
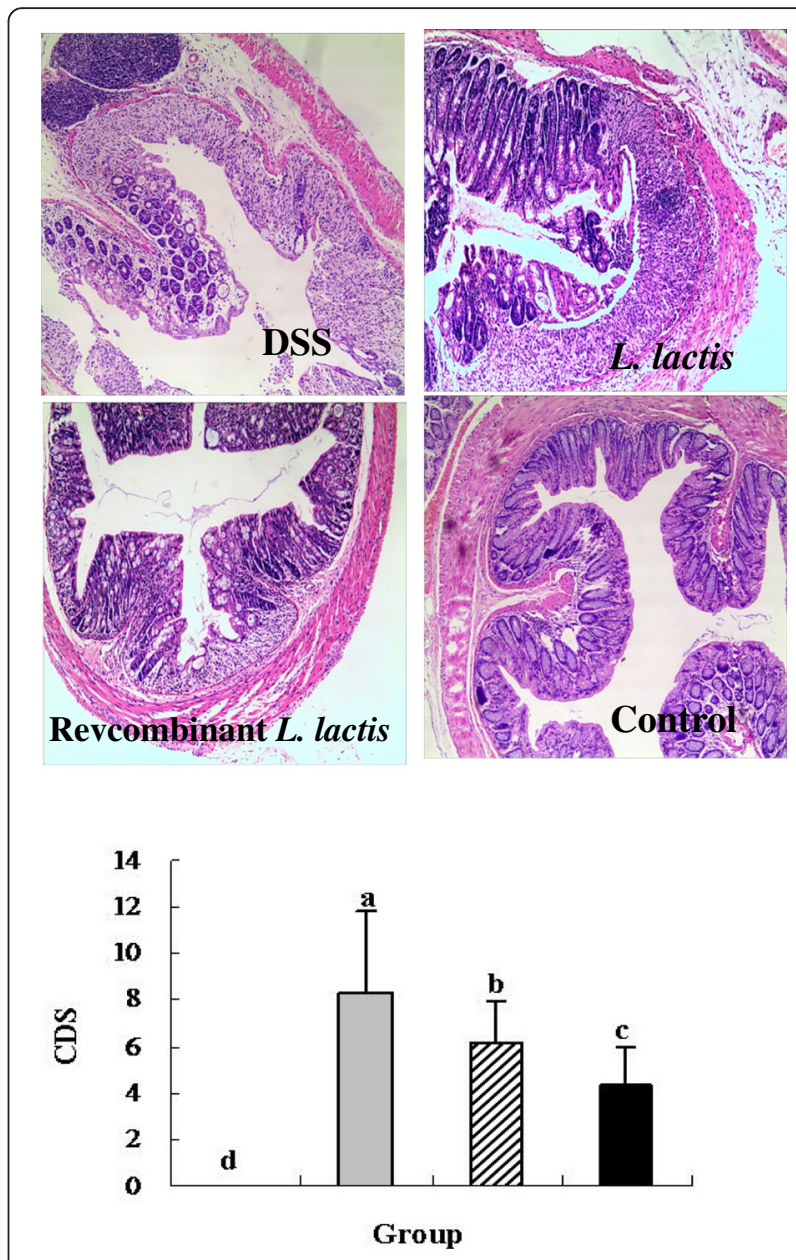

Fig. 3 Effect of oral administration of L. lactis NZ9000 (pNZ8148-plGF-I I $_{3}$ on histopathological changes and colonic damage score in mice $(n=6)$ treated with DSS-induced colitis. The statistical differences between groups were evaluated by one-way ANOVA with Duncan's multiple comparison. Group 1 (control $\square$ ) received normal drinking water. Group 2 (DSS $\square$ received DSS solution in drinking water. Group 3 (L. lactis $\square$ ) received the same treatment of DSS as Group 2. Meanwhile, these mice orally administered with L. lactis NZ9000 (pNZ8148). Group 4 (recombinant L. lactis $\square$ received the same treatment of DSS as Group 2. Meanwhile, these mice orally administered with L. lactis NZ9000 (pNZ8148-p/GF-1 I $_{3}$ ). Same letters between the groups indicate no statistically significant difference $(P>0.05)$, and different letters indicate statistically significant difference $(P<0.05)$

endotoxaemia [29]. Furthermore, IGF-I treatment restored gut weight to control levels and increased the number of crypt mitoses in rats with colon anastomoses [30]. In the present study, oral administration

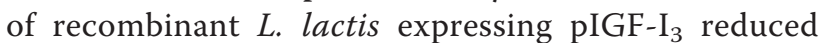
intestinal damage, and maintained the relative integrity of intestinal tract in DSS-treated mice.

Although oral administration of recombinant $L$. lactis expressing pIGF-I $_{3}$ significantly increased colon length and reduced CDS compared with the DSS group, the colon length and CDS was only partially improved. This 
may perhaps be associated with the choice of animal models. In the present study, an acute DSS model of colitis is induced by continuous administration of $5 \%$ DSS for 7 consecutive days. However, susceptibility of mice to DSS was affected by the concentration and molecular weight of DSS, genetic and microbiological factors of animals [31]. These were likely to influence the results of recombinant $L$. lactis expressing pIGF$\mathrm{I}_{3}$ treatment. Genetic variations were well known to be important in intestinal dysfunction, such as IBD. IL-10-deficient (IL-10-/-) mice, a gene-targeted mutation, spontaneously develop a chronic enterocolitis due to a dysregulated immune response to ordinary enteric antigens [32]. This model might be more suitable to evaluate biological activity of the rpIGF-I ${ }_{3}$.

\section{Colonic myeloperoxidase activity analysis}

Myeloperoxidase (MPO) is an enzyme produced in leukocytes, and its activity is linearly related to neutrophil infiltration of the colon as an index of inflammatory response under pathological conditions [33, 34]. In the present study, DSS treatment significantly increased MPO activity by approximately $65.51 \%$ compared with the control group $(P<0.05)$, and the L. lactis group

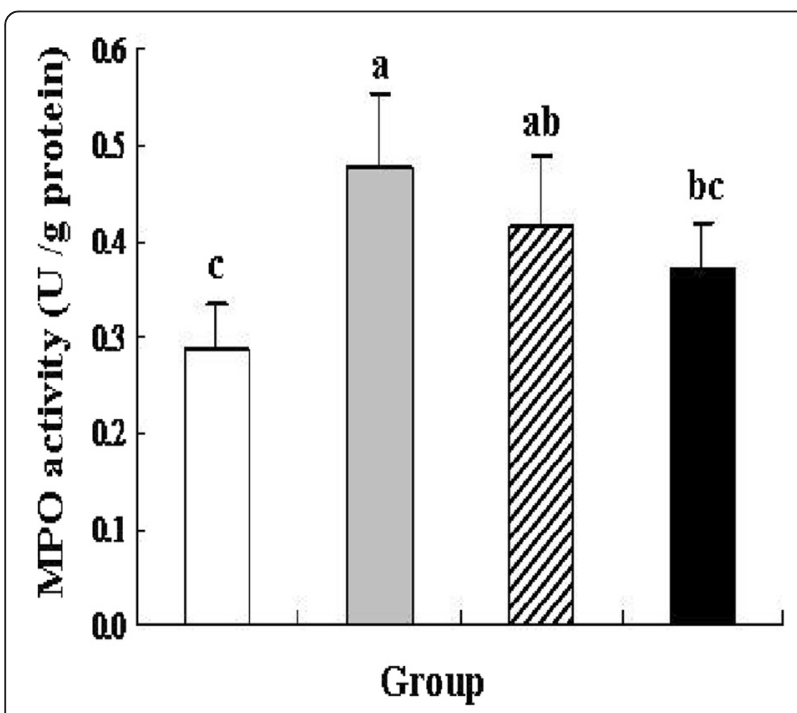

Fig. 4 Effect of L. lactis NZ9000 (pNZ8148-plGF-I ) on colonic MPO activity in mice $(n=6)$ treated with DSS-induced colitis. The statistical differences between groups were evaluated by one-way ANOVA with Duncan's multiple comparison. Group 1 (control received normal drinking water. Group 2 (DSS $\square$ ) received DSS solution in drinking water. Group 3 (L. lactis $\square$ ) received the same treatment of DSS as Group 2. Meanwhile, these mice orally administered with L. lactis NZ9000 (pNZ8148). Group 4 (recombinant L. lactis received the same treatment of DSS as Group 2. Meanwhile, these mice orally administered with L. lactis NZ9000 (pNZ8148-pIGF-I / ). Same letters between the groups indicate no statistically significant difference $(P>0.05)$, and different letters indicate statistically significant difference $(P<0.05)$ revealed a reduction trend on MPO activity (Fig. 4). Oral

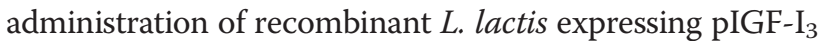
significantly reduced MPO activity by approximately 20.83 \% compared with the DSS group $(P<0.05)$, and showed no significant difference compared with the control group. A similar result was shown that IGF-I inhibited the increases of gastric MPO activity and immunofluorescence intensity of MPO in the gastric mucosa, and reduced stress-induced mucosal injury in mice [35]. The results of this study suggested that recombinant $L$. lactis expressing pIGF- $\mathrm{I}_{3}$ has an anti-inflammatory effect, might reduce intestinal mucosa injury partly because of inhibiting the accumulation of neutrophils in the colonic mucosa. In addition, L. lactis as a host bacterium contributed to beneficial effect on recombinant L. lactis expressing $\mathrm{pIGF}-\mathrm{I}_{3}$ in the prevention of intestinal inflammation.

\section{Diamine oxidase activity and occludin level analysis}

Diamine oxidase (DAO) is a cytoplasmic enzyme existing in the villus cytoplasm of intestinal stratum supravasculare. It is released and enters into the bloodstream when the intestinal mucosa is damaged. Therefore, serum DAO activity is often used as a marker of intestinal mucosal integrity [36]. In this study, DSS treatment significantly increased serum DAO activity by approximately $71.21 \%$ compared with the control group $(P<0.05)$, and oral

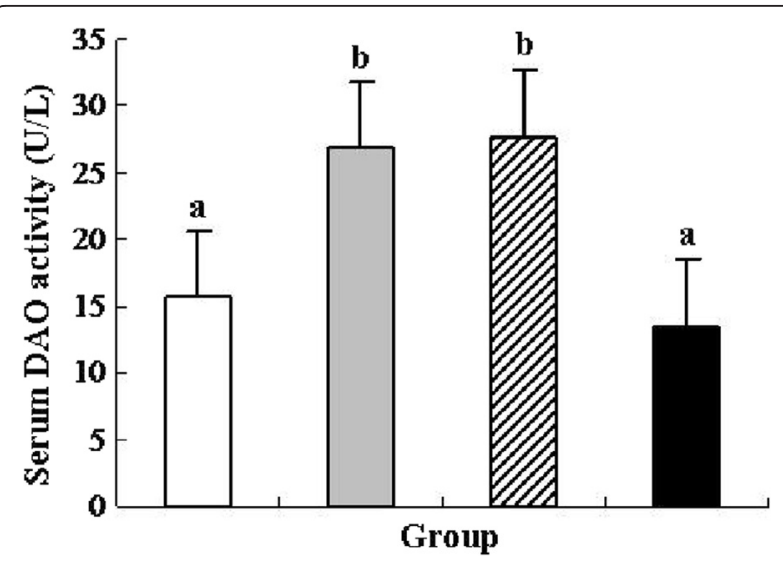

Fig. 5 Effect of L. lactis NZ9000 (pNZ8148-plGF-| $\left.\right|_{3}$ ) on serum DAO activity in mice $(n=6)$ treated with DSS-induced colitis. The statistical differences between groups were evaluated by one-way ANOVA with Duncan's multiple comparison. Group 1 (control $\square$ ) received normal drinking water. Group 2 (DSS $\square$ received DSS solution in drinking water. Group 3 (L. lactis $\square$ ) received the same treatment of DSS as Group 2. Meanwhile, these mice orally administered with L. lactis NZ9000 (pNZ8148). Group 4 (recombinant L. lactis

received the same treatment of DSS as Group 2. Meanwhile, these mice orally administered with L. lactis NZ9000 (pNZ8148-plGF-I 3 ). Same letters between the groups indicate no statistically significant difference $(P>0.05)$, and different letters indicate statistically significant difference $(P<0.05)$ 
administration of $L$. lactis did not inhibit the increase of DAO activity (Fig. 5). However, oral administration of

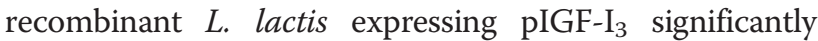
reduced DAO activity by approximately $49.68 \%$ compared with the DSS group $(P<0.05)$. No significant difference was found between the recombinant $L$. lactis and control groups.

Tight junction (TJ) is the most important structure of intestinal barrier. It maintains cell polarity and regulates the permeability of ions, macromolecules, and cells through the paracellular pathway [37]. Occludin is an integral membrane protein localizing at TJ, and performs important functions in $\mathrm{TJ}$ assembly and maintenance [38]. Colonic occludin concentration was also measured in colon tissue. DSS treatment significantly decreased occludin level by approximately $33.53 \%$ compared with the control group $(P<0.05)$ (Fig. 6). As vector control, $L$. lactis strain treatment enhanced occludin level compared with the DSS group, but no significant difference was found between the two groups. Oral administration of recombinant $L$. lactis expressing $\mathrm{pIGF}-\mathrm{I}_{3}$ significantly increased occludin level by approximately $31.25 \%$ compared with the DSS group $(P<0.05)$. No significant difference was found between the recombinant $L$. lactis and control groups.

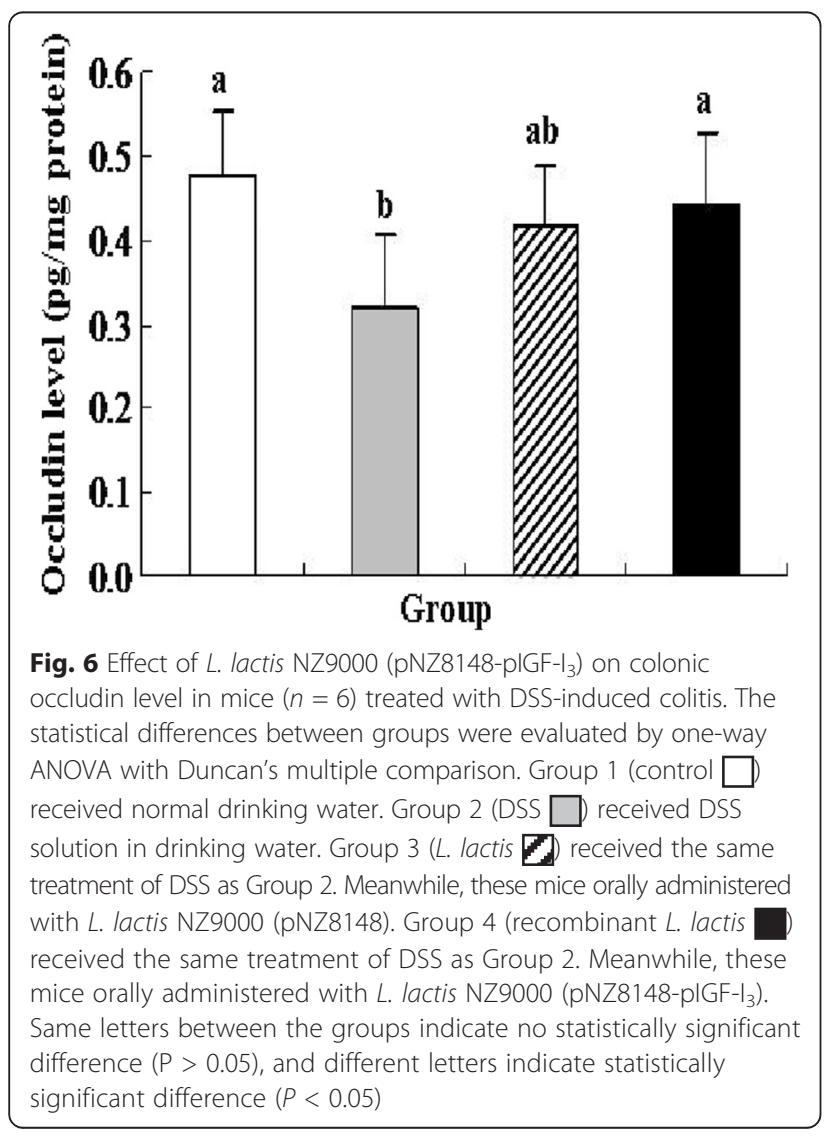

IGF-I has been shown to maintain a paracellular barrier function in cells by the expression and distribution of $\mathrm{TJ}$ proteins and inhibit the increase of plasma DAO activity $[39,40]$. In the present study, oral administration of recombinant $L$. lactis expressing $\mathrm{pIGF} \mathrm{I}_{3}$ prevented the increase of serum DAO activity, enhanced colonic occludin level in mice with colitis, and regulated their levels near to normal concentration. The results showed the consistency with histological examinations. These suggested that oral administration of recombinant $L$. lactis expressing $\mathrm{pIGF}^{-\mathrm{I}_{3}}$ protected the intestinal barrier and integrity, and decreased colitis-induced elevated epithelial permeability.

\section{Conclusions}

In this study, we constructed recombinant $L$. lactis expressing $\mathrm{pIGF}-\mathrm{I}_{3}$ and investigated its effect on intestinal regeneration and repair by using a mouse model of DSS-induced colitis. The results indicated that rpIGF-I ${ }_{3}$ has good biological activity. Oral administration of recombinant $L$. lactis expressing $\mathrm{pIGF} \mathrm{I}_{3}$ attenuated DSS-induced colitis and protected intestinal function by improving CDS, MPO and DAO activities, and inhibiting the increase of colonic occludin level. These suggested that IGF-I expressed in L. lactis could be a good way to treat intestinal diseases.

\section{Methods}

Bacterial strains, plasmids, and growth conditions

L. lactis NZ9000 and plasmid pNZ8148 of the NICE system were purchased from NIZO Food Research. $L$. lactis was grown as a host bacterium in an M17 medium (Difco, Sparks, Maryland, USA) supplemented with 0.5 $\%(\mathrm{w} / \mathrm{v})$ glucose at $30{ }^{\circ} \mathrm{C}$ without agitation. Escherichia coli MC1061 was used as an intermediate cloning host and grown in Luria-Bertani medium with agitation at 37 ${ }^{\circ} \mathrm{C}$. Chloramphenicol was used at a concentration of 10 $\mu \mathrm{g} / \mathrm{mL}$ to select recombinant strains.

\section{Optimization of codon and construction of recombinant L. lactis}

pIGF-I is a small protein composed of 70 amino acid residues with a molecular weight of $7.5 \mathrm{kDa}$. In order to prevent pIGF-I degradation by cellular enzyme, three copies of mature pIGF-I (pIGF-I ${ }_{3}$ ) with the same nucleotide sequence were designed by tandem repeat strategy according to pIGF-I mRNA (GenBank accession no. M31175.1), and separated by a 18 bp linker that yields the amino acid sequence GGGGSG between the copies of pIGF-I. The gene sequence of the designed pIGF- $\mathrm{I}_{3}$ was further optimized based on codon bias of L. lactis (http://www.kazusa.or.jp/codon), and low-usage codons were replaced by high-usage ones. NcoI restriction site (CCATGG) containing a start codon (ATG) was added 
to the $5^{\prime}$ end of the first copy, a stop codon (TAA) and HindIII restriction site (AAGCTT) were added to the 3' end of the third copy. Furthermore, the $\mathrm{G}+\mathrm{C}$ content was adjusted to 40 to $70 \%$, and the resulting fragment (665 bp) was synthesized by Shanghai Shengong Biotechonology (Shanghai, China).

The resulting fragment was cloned into $\mathrm{NcoI}$ and HindIII sites of pNZ8148 vector, and this recombinant vector was transformed into E. coli MC1061. The colonies were selected by resistance to chloramphenicol, confirmed by digestion with NcoI and HindIII, and further sequenced by Invitrogen (Shanghai, China). The positive plasmid named pNZ8148-pIGF- $\mathrm{I}_{3}$ was then transformed into L. lactis NZ9000 by electroporation.

\section{Expression and identification of rpIGF- $I_{3}$ in L. lactis}

The recombinant protein of $\mathrm{pIGF}^{-\mathrm{I}_{3}}$ was identified by SDS-PAGE and Western blot as previously described [41]. Briefly, L. lactis NZ9000 (pNZ8148-pIGF-I ${ }_{3}$ ) and $L$. lactis NZ9000 (pNZ8148) were inoculated (3\% v/v) in fresh medium and grown to an optical density at $\mathrm{OD}_{600}$ $=0.4$. Then these strains were induced with $10 \mathrm{ng} / \mathrm{mL}$ of nisin (Sigma-Aldrich, USA) and continued to grow for 3 h. After harvested by centrifugation, the strains were suspended in $10 \mathrm{mM}$ Tris- $\mathrm{HCl}$ buffer $(\mathrm{pH}$ 8.0) containing $1 \mathrm{mg} / \mathrm{mL}$ lysozyme and incubated on ice for $30 \mathrm{~min}$. The strain extracts were obtained by centrifugation for $10 \mathrm{~min}$, and $10 \mu \mathrm{L}$ of aliquots was analyzed by using $10 \%$ SDS-PAGE. Subsequently, the gel with proteins was transferred to polyvinylidene fluoride membrane (Millipore, Bedford, MA, USA) using a semidry blotting apparatus (Bio-Rad, Hercules, CA, USA). The membrane was incubated with primary anti-IGF-I monoclonal antibody (Abcam, Cambridge, MA, USA) and HRP-conjugated goat polyclonal secondary antibody (Abcam), followed by 3,3'diaminobenzidine as the substrate for visualizing bands.

\section{Stains preparation for animal experiment}

L. lactis NZ9000 (pNZ8148-pIGF-I ${ }_{3}$ ) and L. lactis NZ9000 (pNZ8148) were grown and induced as described above. Stains were collected and washed three times with $0.01 \mathrm{~mol} / \mathrm{L}$ sterile phosphate-buffered saline (PBS) after centrifugation. Finally, L. lactis NZ9000 (pNZ8148-pIGF- $\mathrm{I}_{3}$ ) and L. lactis NZ9000 (pNZ8148) were suspended in PBS to a concentration of $4 \times 10^{12}$ CFU, respectively.

\section{Animals and DSS-induced colitis}

Eight-week-old female BALB/c mice were purchased from SLAC Laboratory Animal Central (Shanghai, China). These pathogen-free mice were housed in filtertop cages at experimental animal room under standard condition, and were provided with ad libitum water and food. All animal protocols were carried out in strict accordance with the guidelines of the Animal Care and Use Committee of Zhejiang, China, and approved by the Committee on the Ethics of Animal Experiments of Zhejiang Academy of Agricultural Sciences, China.

Animals were randomly allotted in five groups, eight mice per group. Mice were treated at 6 weeks of age. Group 1 (control group) received normal drinking water for 10 days. Group 2 (DSS group) received $5 \%$ w/v DSS solution (MW 36,000-50,000; MP Biomedicals, LLC, Illkirch, France) in drinking water for 7 consecutive days and followed with normal drinking water for 3 days. Group 3 (L. lactis group) received the same treatment of DSS as Group 2. Meanwhile, these mice were orally administered with $4 \times 10^{12} \mathrm{CFU}$ of $L$. lactis NZ9000 (pNZ8148) for 10 days. Group 4 (recombinant L. lactis group) received the same treatment of DSS as Group 2. Meanwhile, these mice were orally administered with $4 \times 10^{12}$ CFU of L. lactis NZ9000 (pNZ8148-pIGF-I I $_{3}$ ) for 10 days.

All mice were anesthetized with pentobarbital sodium and killed on the 11th day of the experiment. The colons of all mice were removed, and the length was measured. In addition, colon and blood samples of six mice in each group were randomly selected for the following analysis. Samples of the distal colon approximately $1 \mathrm{~cm}$ were immersion-fixed for $24 \mathrm{~h}$ in $10 \% \mathrm{v} / \mathrm{v}$ formalin buffer for histological assay. Other colonic segments were frozen at $-80{ }^{\circ} \mathrm{C}$ to analyze MPO activity, and occludin level. Before they were killed, blood samples of mice were collected by orbital puncture on the 11th day of the experiment. Serum was obtained for analysis of DAO activity by centrifugation at $1500 \times g$ for $15 \mathrm{~min}$ at $4{ }^{\circ} \mathrm{C}$.

\section{Histology analysis for colonic damage score}

Tissue samples of colon were embedded in paraffin following standard histology procedures. Subsequently, the blocks were cut into sections of $4 \mu \mathrm{m}$ thickness, which were stained routinely with hematoxylin and eosin, and microscopically examined. Colonic damage was graded in a blinded manner as described by Dieleman et al. [42]. The colonic sections were briefly assessed based on the amount of inflammation (acute and chronic; scored from 0 to 3), the depth of inflammation, and the amount of crypt damage or regeneration (scored from 0 to 4). The results were quantified for the percentage involvement in the disease process as follows: (1) 1 to $25 \%$, (2) 26 to $50 \%$, (3) 51 to $75 \%$, and (4) 76 to $100 \%$. The score of each colonic section was provided for each feature by establishing the product of the grade for that feature and the percentage involvement. Finally, the colonic damage score (CDS) of each mice was the sum of these scores. 


\section{Determination of colonic myeloperoxidase activity and occludin level}

MPO activity was measured in colon tissue using the Assay Kit following the manufacturer's instruction (Nanjing Jiancheng Bio-engineering Co., Ltd., China). One unit of MPO activity was defined as $\mathrm{H}_{2} \mathrm{O}_{2}$ broken into $1 \mathrm{~mol}$ in each gram of tissue at $37^{\circ} \mathrm{C}$, and the result was finally expressed as units per gram of total colon protein. The occludin level of colon tissue was analyzed using the Mouse ELISA kit (Nanjing Jiancheng Bioengineering Co., Ltd.) and expressed as nanograms per milligram of total colon protein.

\section{Measurement of serum diamine oxidase activity}

The activity of serum DAO was further measured using the Assay Kit following the manufacturer's instruction (Nanjing Jiancheng Bio-engineering Co., Ltd.). DAO activity was expressed as units per liter of serum volume.

\section{Statistical analysis}

All data were presented as means \pm standard deviation for each group. The statistical differences between groups were evaluated by one-way ANOVA with Duncan's multiple comparison. $P<0.05$ was considered statistically significant.

\section{Abbreviations \\ CDS: Colonic damage score; DAO: Diamine oxidase; DSS: Dextran sulfate sodium; IGF-I: Insulin-like growth factor I; L. lactis: Lactococcus lactis; MPO: Myeloperoxidase; PBS: Phosphate-buffered saline; pIGF-I: Porcine insulin-like growth factor I; $_{\text {; }}$ GF-13: Three same genes of mature porcine IGF-I; rplGF-I ${ }_{3}$ : Recombinant plGF-I $\left.\right|_{3}$; SDS-PAGE: Sodium dodecyl sulfate-polyacrylamide gel electrophoresis.}

\section{Competing interests}

All authors declare that we have no conflicts of interest on this paper.

\section{Authors' contributions}

LS performed experiments, analyzed data, and drafted the manuscript. LY and DB analyzed data, XZ designed experiments. All authors read and approved the final manuscript.

\section{Acknowledgements}

This work was supported by a project from an earmarked fund for Modern Agro-industry Technology Research System, China (CARS-36), National Key Technology R \& D Program, China (2012BAD39B03-04), Natural Science Foundation of Zhejiang Province, China (LQ12C17004), and Special Scientific Research Fund of Public Welfare Profession (Agriculture), China (201403047),

Received: 16 September 2015 Accepted: 22 February 2016

Published online: 01 March 2016

\section{References}

1. Tavakkol A, Simmen FA, Simmen RC. Porcine insulin-like growth factor-I (plGF-l): complementary deoxyribonucleic acid cloning and uterine expression of messenger ribonucleic acid encoding evolutionarily conserved IGF-I peptides. Mol Endocrinol. 1988;2:674-81.

2. Chapman IM, Hartman ML, Pieper KS, Skiles EH, Pezzoli SS, Hintz RL, et al. Recovery of growth hormone release from suppression by exogenous insulin-like growth factor I (IGF-I): evidence for a suppressive action of free rather than bound IGF-I. J Clin Endocrinol Metab. 1998;83:2836-42.
3. Pedroso FL, de Jesus-Ayson EG, Cortado HH, Hyodo S, Ayson FG. Changes in mRNA expression of grouper (Epinephelus coioides) growth hormone and insulin-like growth factor I in response to nutritional status. Gen Comp Endocrinol. 2005;145:237-46.

4. Li X, Yin J, Li D, Chen X, Zang J, Zhou X. Dietary supplementation with zinc oxide increases lgf-I and Igf-I receptor gene expression in the small intestine of weanling piglets. J Nutr. 2006;136:1786-91.

5. Laburthe M, Rouyer-Fessard C, Gammeltoft S. Receptors for insulin-like growth factors I and II in rat gastrointestinal epithelium. Am J Physiol. 1988;254(3 Pt 1):G457-62.

6. Mairet-Coello G, Tury A, DiCicco-Bloom E. Insulin-like growth factor-I promotes $\mathrm{G}(1) / \mathrm{S}$ cell cycle progression through bidirectional regulation of cyclins and cyclin-dependent kinase inhibitors via the phosphatidylinositol 3-kinase/Akt pathway in developing rat cerebral cortex. J Neurosci. 2009;29:775-88.

7. Yu Y, Mu J, Fan Z, Lei G, Yan M, Wang S, et al. Insulin-like growth factor I enhances the proliferation and osteogenic differentiation of human periodontal ligament stem cells via ERK and JNK MAPK pathways. Histochem Cell Biol. 2012;137:513-25.

8. Lang CH, Frost RA, Svanberg E, Vary TC. IGF-I/IGFBP-3 ameliorates alterations in protein synthesis, elF4E availability, and myostatin in alcohol-fed rats. Am J Physiol Endocrinol Metab. 2004;286:E916-26.

9. Kuemmerle JF. Endogenous IGF-I protects human intestinal smooth muscle cells from apoptosis by regulation of GSK-3 beta activity. Am J Physiol Gastrointest Liver Physiol. 2005;288:G101-10.

10. Wit JM, Walenkamp MJ. Role of insulin-like growth factors in growth, development and feeding. World Rev Nutr Diet. 2013;106:60-5.

11. Moriyama S, Ayson FG, Kawauchi H. Growth regulation by insulin-like growth factor-I in fish. Biosci Biotechnol Biochem. 2000;64:1553-62.

12. Donovan SM, Odle J. Growth factors in milk as mediators of infant development. Annu Rev Nutr. 1994;14:147-67.

13. Alexander AN, Carey HV. Oral IGF-I enhances nutrient and electrolyte absorption in neonatal piglet intestine. Am J Physiol. 1999;277:G619-25.

14. Hartke $J L$, Monaco MH, Wheeler MB, Donovan SM. Effect of a short-term fast on intestinal disaccharidase activity and villus morphology of piglets suckling insulin-like growth factor-1 transgenic sows. J Anim Sci. 2005;83:2404-13.

15. Chen T, Zheng F, Tao J, Tan S, Zeng L, Peng X, et al. Insulin-Like Growth Factor- I Contributes to Mucosal Repair by $\beta$-Arrestin2-Mediated Extracellular Signal-Related Kinase Signaling in Experimental Colitis. Am J Pathol. 2015; 185:2441-2453.

16. Cool JC, Dyer JL, Xian CJ, Butler RN, Geier MS, Howarth GS. Pre-treatment with insulin-like growth factor-I partially ameliorates 5-fluorouracil-induced intestinal mucositis in rats. Growth Horm IGF Res. 2005;15:72-82.

17. Wilkins HR, Ohneda K, Keku TO, D'Ercole AJ, Fuller CR, Williams KL. Reduction of spontaneous and irradiation-induced apoptosis in small intestine of IGF-I transgenic mice. Am J Physiol Gastrointest Liver Physiol. 2002;283:G457-64

18. Warzecha Z, Dembinski A, Ceranowicz P, Konturek SJ, Tomaszewska R, Stachura J, et al. IGF-I stimulates production of interleukin-10 and inhibits development of caerulein-induced pancreatitis. J Physiol Pharmacol. 2003;54:575-90.

19. Choi SP, Park YC, Lee J, Sim SJ, Chang HN. Effects of L-arginine on refolding of lysine-tagged human insulin-like growth factor I expressed in Escherichia coli. Bioprocess Biosyst Eng. 2012;35:255-63.

20. Floch MH, Walker WA, Madsen K, Sanders ME, Macfarlane GT, Flint HJ. Recommendations for probiotic use-2011 update. J Clin Gastroenterol. 2011;45:S168-71.

21. Broadbent JR, Brighton C, McMahon DJ, Farkye NY, Johnson ME, Steele JL. Microbiology of Cheddar cheese made with different fat contents using a Lactococcus lactis single-strain starter. J Dairy Sci. 2013;96:4212-22.

22. Bermúdez-Humarán LG. Lactococcus lactis as a live vector for mucosal delivery of therapeutic proteins. Hum Vaccin. 2009;5:264-7.

23. Klijn N, Weerkamp AH, de Vos WM. Genetic marking of Lactococcus lactis shows its survival in the human gastrointestinal tract. Appl Environ Microbiol. 1995;61:2771-4.

24. Liu S, Li Y, Xu Z, Wang Y. Immune responses elicited in mice with recombinant Lactococcus lactis expressing F4 fimbrial adhesin FaeG by oral immunization. Vet Res Commun. 2010;34:491-502. 
25. Chung HL, Yue GG, To KF, Su YL, Huang Y, Ko WH. Effect of Scutellariae Radix extract on experimental dextran-sulfate sodium-induced colitis in rats. World J Gastroenterol. 2007;13:5605-11.

26. Baumrucker CR, Hadsell DL, Blum JW. Effects of dietary insulin-like growth factor I on growth and insulin-like growth factor receptors in neonatal calf intestine. J Anim Sci. 1994;72:428-33.

27. Howarth GS, Xian CJ, Read LC. Insulin-like growth factor-I partially attenuates colonic damage in rats with experimental colitis induced by oral dextran sulphate sodium. Scand J Gastroenterol. 1998;33:180-90.

28. Rijcken E, Fuchs $T$, Sachs L, Kersting CM, Bruewer M, Krieglstein CF. Insulin-like growth factor I-coated sutures improve anastomotic healing in an experimental model of colitis. Br J Surg. 2010;97:258-65.

29. Lorenzo-Zúñiga V, Rodríguez-Ortigosa CM, Bartolí R, Martínez-Chantar ML, Martínez-Peralta L, Pardo A, et al. Insulin-like growth factor I improves intestinal barrier function in cirrhotic rats. Gut. 2006;55:1306-12

30. Egger B, Inglin R, Zeeh J, Dirsch O, Huang Y, Büchler MW. Insulin-like growth factor I and truncated keratinocyte growth factor accelerate healing of left-sided colonic anastomoses. Br J Surg. 2001;88(1):90-8.

31. Perše M, Cerar A. Dextran sodium sulphate colitis mouse model: traps and tricks. J Biomed Biotechnol. 2012;2012:718617.

32. Davidson NJ, Fort MM, Müller W, Leach MW, Rennick DM. Chronic colitis in |L-10-/- mice: insufficient counter regulation of a Th1 response. Int Rev Immunol. 2000;19:91-121.

33. Villegas I, de la Lastra C A, Oriales A, La Casa C. A new flavonoid derivative, dosmalfate, attenuates the development of dextran sulphate sodiuminduced colitis in mice. Int Immunopharmacol. 2003:3:1731-41.

34. Gustapane M, Cardillo MT, Biasillo G, Biasucci LM. Myeloperoxidase as possible diagnostic and prognostic marker of acute coronary syndrome. Recenti Prog Med. 2011;102:447-50.

35. Zhao J, Harada N, Sobue K, Katsuya H, Okajima K. Insulin-like growth factor-I reduces stress-induced gastric mucosal injury by inhibiting neutrophil activation in mice. Growth Horm IGF Res. 2009;19:136-45.

36. Luk GD, Bayless TM, Baylin SB. Diamine oxidase (histaminase). A circulating marker for rat intestinal mucosal maturation and integrity. J Clin Invest. 1980;66:66-70.

37. Anderson JM, Van Itallie CM. Tight junctions and the molecular basis for regulation of paracellular permeability. Am J Physiol. 1995;269:G467-75.

38. Balda MS, Flores-Maldonado C, Cereijido M, Matter K. Multiple domains of occludin are involved in the regulation of paracellular permeability. J Cell Biochem. 2000;78:85-96.

39. Hatakeyama N, Kojima T, Iba K, Murata M, Thi MM. IGF-I regulates tightjunction protein claudin-1 during differentiation of osteoblast-like MC3T3-E1 cells via a MAP-kinase pathway. Cell Tissue Res. 2008;334:243-54.

40. Mitsui R, Fujita-Yoshigaki J, Narita T, Matsuki-Fukushima M, Satoh K, Qi B, et al. Maintenance of paracellular barrier function by insulin-like growth factorI in submandibular gland cells. Arch Oral Biol. 2010:55:963-9.

41. Liu S, Li Y, Xu Z, Wang Y. Subcutaneous or oral immunization of mice with Lactococcus lactis expressing F4 fimbrial adhesin FaeG. J Vet Med Sci. 2013;75:779-84.

42. Dieleman LA, Palmen MJ, Akol H, Bloemena E, Peña AS, Meuwissen SG, et al. Chronic experimental colitis induced by dextran sulphate sodium (DSS) is characterized by Th1 and Th2 cytokines. Clin Exp Immunol. 1998:114:385-91.

\section{Submit your next manuscript to BioMed Central and we will help you at every step:}

- We accept pre-submission inquiries

- Our selector tool helps you to find the most relevant journal

- We provide round the clock customer support

- Convenient online submission

- Thorough peer review

- Inclusion in PubMed and all major indexing services

- Maximum visibility for your research

Submit your manuscript at www.biomedcentral.com/submit

) Biomed Central 